 \\ Respiratory and Pulmonary Medicine
}

ORIGINAL ARTICLE

\section{Posterior Vitreous Detachment Prevalence in Patients with Chronic Obstructive Pulmonary Disease

\author{
Hatice Daldal ${ }^{1}$, Musa Yiğit ${ }^{2 *}$ and Yavuz Bardak ${ }^{3}$
}

${ }^{1}$ Department of Ophthalmology, Medicine School Education and Research Hospital, Uşak University, Uşak, Turkey

${ }^{2}$ Department of Ophthalmology, Karaman State Hospital, Karaman, Turkey

${ }^{3}$ Department of Ophthalmology Clinic, İstanbul Ümraniye Education and Research Hospital, İstanbul, Turkey

*Corresponding author: Musa Yiğit, Department of Ophthalmology, Karaman State Hospital, Karaman, Turkey, Tel: +(90)-05053470851, Fax: +(90)-276-2238475

\begin{abstract}
Purpose: The aim of this study is to evaluate the prevalence of posterior vitreous detachment (PVD) in chronic obstructive pulmonary disease (COPD) patients.

Material and methods: 142 eyes of 71 consecutive patients with COPD who are applied to ophthalmology clinic were included in the retrospective study from January 2012 to August 2013. Trauma, ophthalmologic surgery history, diabetic retinopathy, uveitis, chorioretinitis, retinitis pigmentosa, retinal detachment and tears in the anamnesis and ophthalmologic examination were excluded from study.

The visual acuity of the patients was assessed using Snellen chart. Intraocular pressure was measured with applanation tonometry. Fundus examination was performed using $+90 \mathrm{D}$ lens after pupil dilation with $0.5 \%$ tropicamide following biomicroscopic anterior segment examination. All patients underwent peripheral retinal examination with Goldmann three-mirror lens to detect the presence of retinal tear. $A$ and $B$ mode ultrasonography was performed to patients.

Results: 142 eyes of 71 patients, 5 of whom were female $(7 \%)$ and 66 of whom were male $(93 \%)$ were included to the study. The patients were aged between $43-80$ years and the mean age of the cases was $62.61 \pm 8.34$.

The average visual acuity was found as $0.78 \pm 0.25(0.05-1)$. Mean intraocular pressure was found as $12.5 \pm 2.26 \mathrm{mmHg}$ (8-18 $\mathrm{mmHg})$. PVD was detected in 87 eyes of 142 eyes. The prevalence of PVD was found as $61.26 \% .46(52.87 \%)$ patients of 87 cases were symptomatic.
\end{abstract}

Conclusion: The PVD prevalence was higher in this age group in COPD patients than normal population. The reason of this may be concussion by increased cough reflex and amount in COPD. Pathologies that may cause increased cough reflex like COPD can be evaluated for risk factors and tendency to PVD.
In conclusion, PVD is an important situation because it may lead to vitreoretinal pathologies like retinal tear, retinal detachment, intravitreal hemorrhage, macular hole. Therefore COPD patients should be evaluated by an ophthalmologist for early diagnosis and treatment.

\section{Keywords}

Chronic obstructive pulmonary disease, Vitreous detachment

\section{Introduction}

Chronic obstructive pulmonary disease (COPD) is a common respiratory condition characterized by airflow limitation $[1,2]$. It affects more than 5 percent of the population and is associated with high morbidity and mortality [3].

The most important age-related change in vitreous is posterior vitreous detachment (PVD) [4]. PVD is defined as separation of posterior vitreous cortex from the internal limiting membrane of the retina [5].

PVD is important because it may cause retinal detachment, spontaneous vitreous or retinal hemorrhage due to retinal tears. Between $8 \%$ and $26 \%$ of patients with acute PVD symptoms have a retinal tear at the time of the initial examination [6-10]. There is a direct correlation between the amount of vitreous hemorrhage and the likelihood of a retinal tear [11]. Patients with an acute PVD who have no reported retinal breaks on presentation have a $2 \%$ to $5 \%$ chance of experiencing a

Citation: Daldal H, Yiğit M, Bardak Y (2019) Posterior Vitreous Detachment Prevalence in Patients with Chronic Obstructive Pulmonary Disease. Int J Respir Pulm Med 6:118. doi.org/10.23937/23783516/1410118

Accepted: August 29, 2019; Published: August 31, 2019

Copyright: (c) 2019 Daldal H, et al. This is an open-access article distributed under the terms of the Creative Commons Attribution License, which permits unrestricted use, distribution, and reproduction in any medium, provided the original author and source are credited 


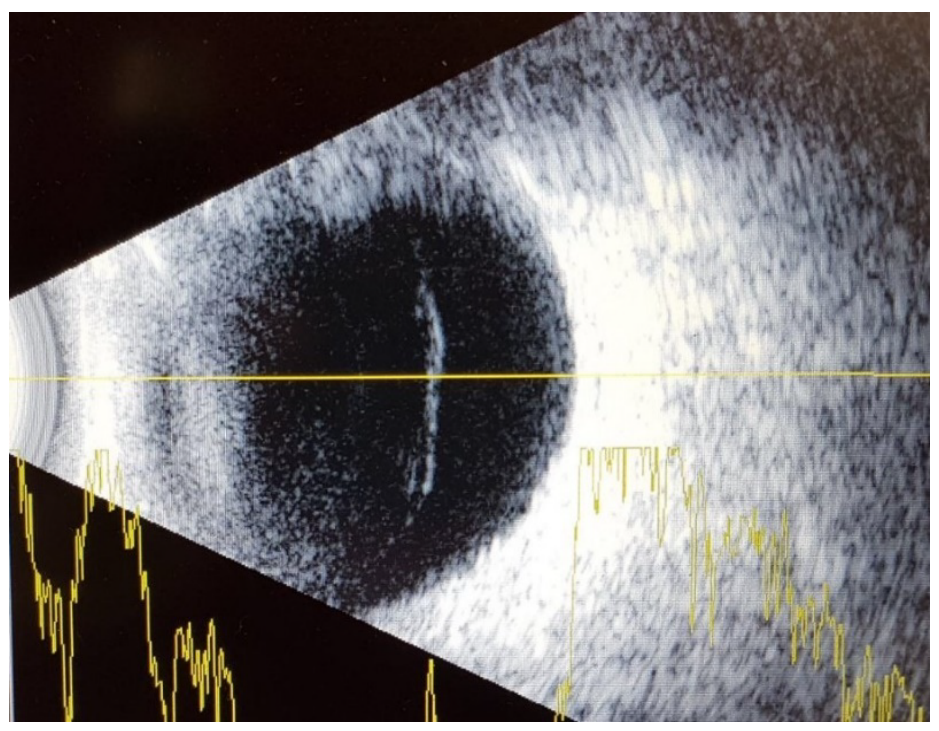

Figure 1: Posterior vitreous detachment.

detected (missed or new) break in the weeks that follow $[8,12,13]$. Therefore, it is necessary to closely follow-up of such these cases.

In this study, the prevalence of PVD in COPD patients was evaluated.

\section{Materials and Methods}

Ethics committee approval was obtained from Süleyman Demirel University Ethical Committee.

142 eyes of 71 consecutive patients with COPD who are applied to Dinar State Hospital ophthalmology clinic were included in the retrospective study from January 2012 to August 2013. Trauma, ophthalmologic surgery history, diabetic retinopathy, uveitis, chorioretinitis, retinitis pigmentosa, retinal detachment and tears in the anamnesis and ophthalmologic examination were excluded from study.

The visual acuity of the patients was assessed using Snellen chart. Intraocular pressure was measured with applanation tonometry. Fundus examination was performed using +90D lens after pupil dilation with $0.5 \%$ tropicamide following biomicroscopic anterior segment examination. All patients underwent peripheral retinal examination with Goldmann three-mirror lens to detect the presence of retinal tear. A and B mode ultrasonography was performed to patients (Figure 1 ).

\section{Results}

142 eyes of 71 patients, 5 of whom were female (7\%) and 66 of whom were male (93\%) were included to the study. The patients were aged between $43-80$ years and the mean age of the cases was $62.61 \pm 8.34$.

The average visual acuity was found as $0.78 \pm 0.25$ (0.05-1). Mean intraocular pressure was found as 12.5 $\pm 2.26 \mathrm{mmHg}(8-18 \mathrm{mmHg})$. PVD was detected in 87 eyes of 142 eyes. The prevalence of PVD was found as $61.26 \% .46(52.87 \%)$ patients of 87 cases were symp- tomatic. There were cataract in $73(51.40 \%)$ eyes, macular macular degeneration in 18 (12.67\%) eyes and glaucoma in 5 (3.52\%) eyes.

\section{Discussion}

Vitreous is a gel-like formation in the posterior part of the eye and vitreous may lose its gel-like consistency. The vitreous gel-like form starts to liquefy with aging and then lacunes occur inside vitreous. After liquefaction of vitreous both shock absorbtion and stability begin decreasing. Liquefied vitreous pass to subhyaloid space especially at macular region and over time posterior vitreous detachment (PVD) develops [14].

PVD is rare in persons under 30 years of age, and it increases from 10 percent between ages 30 and 59, to 27 percent between ages 60 and 69, and to 63 percent in persons age 70 years and older [15].

Foos reported in 1972, in a large post-mortem study of 786 (1572 eyes) adults (above 20 years), that $24.5 \%$ had PVD in one (7\%) or both (17\%) eyes and he found PVD in one or both eyes $0.4 \%$ (20-49 years), $7.2 \%$ (50-59 years), $22 \%$ (60-69 years) and $60 \%$ (70 or more years) [15].

Hayreh found the frequency increased of PVD with age. He defined that the frequency is, in patients younger than 45 years $4.7 \%$, aged $45-65$ years $20.4 \%$ and older than 65 years $58.4 \%$ [16].

Foos [15] and Hayreh [16] also found that PVD was significantly fewer in men than in women and was even affected by other factors such as age and refractive error, however the reason is unclear. According to the study of Larsson, female eyes have relatively reduced hyaluronic acid concentrations and therefore PVD frequency is higher in female eyes than male eyes [17].

Although the majority was male in our study due to high male frequency rate of COPD, the prevalence of PVD was found as $61.26 \%$. 
Rieger reported that PVD developed increasingly with age and higher degrees of myopia [18]. The presence of myopia is associated with a three- to fourfold increased risk of PVD compared with absence of myopia. Chuo, et al. defined that there was no association between PVD and smoking, drinking and hypertension [19].

Trauma, inflammation, vitreous hemorrhage, retinal vascular diseases, hereditary vitreoretinal syndromes effecting type 2 collagen metabolism like Stickler and Marfan syndromes, reduction of hyaluronic acid synthesis dependent on postmenapausal decrease in estrogen levels may cause developing of PVD [20,21].

PVD is significantly more common in postmenopausal women than men; this is thought to be due to the effects of decreased oestrogen on connective tissues such as those within the vitreous gel $[19,22]$.

Due to varying anterior chamber dynamics and probability of intraoperative posterior capsule rupture in cataract surgery, PVD observation may increase [23,24].

This age-related physiological change can, in some cases, result in retinal damage through traction with retinal tears/hemorrhages and/or retinal detachment (RD) when collapse occurs [25]. It should be noted that up to $20 \%$ of PVDs are asymptomatic [26]. The adherence of the vitreous is strongest to the retina around the optic nerve head, at the macula, and at the base of the vitreous (at ora serrata). The vitreous is also adherent to the ciliary body and the posterior lens capsule and traction to these structures can cause structural damage [27]. In the event of a retinal rupture, vitreous fluid can enter the retina through the tear, leading to separation of the neuroretina from the underlying retinal pigment epithelium resulting in RD in $33 \%-46 \%$ of the cases [28]. A recent study has shown that the incidence of retinal tears of $14.5 \%$ and hemorrhages of $22.7 \%$ in patients with symptoms of PVD [29].

Our study included 142 eyes of 71 COPD patients. There were 5 (7\%) females and 66 (93\%) males. Posterior vitreous detachments developed in 87 eyes. The patients ranged in age from 43 to 80 years, with an average age of $62.61 \pm 8.34$. PVD prevalence is found $61.26 \%$ in COPD patients. Of the 87 eyes, 46 (52.87\%) were symptomatic. The PVD prevalence was higher in this age group in COPD patients than normal population. The reason of this may be concussion by increased cough reflex and amount in COPD. Pathologies that may cause increased cough reflex like COPD can be evaluated for risk factors and tendency to PVD.

Main comorbid situations in COPD are skeletal muscle weakness, malnutrition, cachexia, cardiovascular disorders, endocrinological problems (diabetes mellitus, osteoporosis), normositic anemia, depression and pulmoner carcinoma [30].
According to our study, also PVD should be taken into consideration among comorbid disorders in COPD patients.

There is no study in the literature like our study about COPD and PVD.

\section{Conclusion}

PVD is an important situation because it may lead to vitreoretinal pathologies like retinal tear, retinal detachment, intravitreal hemorrhage, macular hole. Therefore COPD patients should be evaluated by an ophthalmologist for early diagnosis and treatment.

\section{References}

1. Buist AS, McBurnie MA, Vollmer WM, Gillespie S, Burney $P$, et al. (2007) International variation in the prevalence of COPD (the BOLD Study): A population-based prevalence study. Lancet 370: 741-750.

2. Gershon AS, Warner L, Cascagnette P, Victor JC, To $T$ (2011) Lifetime risk of developing chronic obstructive pulmonary disease: A longitudinal population study. Lancet 378: 991-996.

3. Centers for Disease Control and Prevention (CDC) (2012) Chronic obstructive pulmonary disease among adults-United States, 2011. MMWR Morb Mortal Wkly Rep 61: 938-943.

4. Sebag J (1997) Classifying posterior vitreous detachment: a new way to look at the invisible. $\mathrm{Br} \mathrm{J}$ Ophthalmol 81: 521.

5. Johnson MW (2012) Posterior vitreous detachment: Evolution and role in macular disease. Retina 32: 174-178.

6. Tasman WS (1968) Posterior vitreous detachment and peripheral retinal breaks. Trans Am Acad Ophthalmol Otolaryngol 72: 217-224.

7. Tani P, Robertson DM, Langworthy A (1980) Rhegmatogenous retinal detachment without macular involvement treated with scleral buckling. Am J Ophthalmol 90: 503-508.

8. Coffee RE, Westfall AC, Davis GH, Mieler WF, Holz ER (2007) Symptomatic posterior vitreous detachment and the incidence of delayed retinal breaks: case series and metaanalysis. Am J Ophthalmol 144: 409-413.

9. Benson WE, Grand MG, Okun E (1975) Aphakic retinal detachment. Management of the fellow eye. Arch Ophthalmol 93: 245-249.

10. Scott IU, Smiddy WE, Merikansky A, Feuer W (1997) Vitreoretinal surgery outcomes. Impact on bilateral visual function. Ophthalmology 104: 1041-1048.

11. Lincoff H, Stopa M, Kreissig I (2004) Ambulatory binocular occlusion. Retina 24: 246-253.

12. Dayan MR, Jayamanne DG, Andrews RM, Griffiths PG (1996) Flashes and floaters as predictors of vitreoretinal pathology: Is follow-up necessary for posterior vitreous detachment? Eye 10: 456-458.

13. van Overdam KA, Bettink-Remeijer MW, Mulder PG, van Meurs JC (2001) Symptoms predictive for the later development of retinal breaks. Arch Ophthalmol 119: 1483-1486.

14. Wilkinson CP (1999) Rhegmatogenous retinal detachment. In: Yanoff M, Duker JS, Ophthalmology 39: 1-8.

15. Foos RY (1972) Posterior vitreous detachment. Trans Am Acad Ophthalmol Otolaryngol 76: 480-497. 
16. Hayreh SS, Jonas JB (2004) Posterior vitreous detachment: clinical correlations. Ophthalmologica 218: 333-343.

17. Larsson L, Osterlin S (1985) Posterior vitreous detachment. A combined clinical and physiochemical study. Graefes Arch Clin Exp Ophthalmol 223: 92-95.

18. Rieger H (1937) Uber die Bedeutung der Aderhautveranderungen fur die Entstehung der Glaskorperabhebung. Graefes Arch Clin Exp Ophthalmol 136: 118-165.

19. Chuo JY, Lee TYY, Hollands H, Morris AH, Reyes RC, et al. (2006) Risk factors for posterior vitreous detachment: $A$ case-control study. Am J Ophthalmol 142: 931-937.

20. Johnson MW (2010) Posterior vitreous detachment: Evolution and complications of its early stages. Am J Ophthalmol 14: 371-382.

21. Kadayıfçılar S (2011) Ageing of the vitreous. Ret-Vit 19: 221-224.

22. Sebag J (1987) Ageing of the vitreous. Eye 1: 254-262.

23. Özertürk $Y(2000)$ Retinal complications and treatment in anterior segment surgery. Ret-Vit 8: 115-121.
24. Atmaca Sönmez P, Atmaca LS, Özyol E (2007) Cystoid macular edema after anterior segment surgery. Ret-Vit 15: 71-75.

25. Schweitzer KD, Eneh AA, Hurst J, Bona MD, Rahim KJ, et al. (2011) Predicting retinal tears in posterior vitreous detachment. Can J Ophthalmol 46: 481-485.

26. Richardson PS, Benson MT, Kirkby GR (1999) The posterior vitreous detachment clinic: Do new retinal breaks develop in the six weeks following an isolated symptomatic posterior vitreous detachment? Eye (Lond) 13: 237-240.

27. Thimons JJ (1992) Posterior vitreous detachment. Optom Clin 2: 1-24.

28. Hollands H, Johnson D, Brox AC, Almeida D, Simel DL, et al. (2009) Acute-onset floaters and flashes: Is this patient at risk for retinal detachment? JAMA 302: 2243-2249.

29. Bond-Tylor M, Jakobsson G, Zetterberg M (2017) Posterior vitreous detachment - prevalence of and risk factors for retinal tears. Clin Ophthalmol 11: 1689-1695.

30. Barnes PJ, Celli BR (2009) Systemic manifestations and comorbidities of COPD. Eur Respir J 33: 1165-1185. 